\title{
Distribution of foraging by female Antarctic fur seals
}

\author{
I. L. Boyd ${ }^{1, *}$, I. J. Staniland ${ }^{1}$, A. R. Martin ${ }^{2}$ \\ ${ }^{1}$ British Antarctic Survey, Natural Environment Research Council, Madingley Road, Cambridge CB3 0ET, United Kingdom \\ ${ }^{2}$ Sea Mammal Research Unit, Gatty Marine Laboratory, University of St. Andrews, St. Andrews, Fife KY16 8LB, \\ United Kingdom
}

\begin{abstract}
The study examined the distribution of critical habitat for foraging by female Antarctic fur seals breeding at the island of South Georgia. Bathymetric features of the continental shelf around the island of South Georgia were an important indicator for the localisation of foraging. This pattern was consistent among years of different prey availability. Lactating females were constrained to forage mainly within $100 \mathrm{~km}$ of the location at which the offspring was being raised. When this constraint was removed at the end of lactation, females foraged to much greater ranges and dispersed to specific regions of the continental shelf east of Patagonia $(>1000 \mathrm{~km})$ and to the northern edge of the Antarctic pack ice $(500 \mathrm{~km})$. The empirical distribution of foraging during the breeding season was used to develop a function that described the foraging distribution for the whole breeding population of females. The result was consistent with past observations from ship-based surveys and it allowed estimation of the spatial impact of breeding female fur seals on krill at South Georgia. This suggested that, in extreme cases and assuming that krill influx is limited, female fur seals could eat most of the krill present in some regions where they forage intensively. However, mean consumption was about one-tenth of the mean density of krill.
\end{abstract}

KEY WORDS: Southern Ocean $\cdot$ Krill $\cdot$ Dispersion $\cdot$ Behavior $\cdot$ Critical habitat $\cdot$ Ice edge $\cdot$ Patagonian Shelf · South Georgia · Predator-prey interactions · Arctocephalus gazella

Resale or republication not permitted without written consent of the publisher

\section{INTRODUCTION}

In many pelagic marine ecosystems, vertebrate homeothermic predators form an important component of the food chain, in terms of abundance, biomass and influence. Additionally, due to their position at the top of marine food chains they have been cited as potential indicators of change in marine ecosystems (Cairns 1987, Montevecchi 1993, Monaghan 1996, Agnew 1997), because they tend to integrate variability in the productivity of the ecosystem across large spatial and temporal scales. In some cases they are also tractable subjects for study and monitoring (Boyd \& Murray 2001, Reid \& Croxall 2001), and the spatial distribution

*Present address: Sea Mammal Research Unit, Gatty Marine Laboratory, University of St. Andrews, St. Andrews, Fife KY16 8LB, United Kingdom. E-mail: ilb@st-andrews.ac.uk of foraging by these predators is important in developing definitions of marine protected areas (Hyrenbach et al. 2000).

The upper trophic levels of the food chain of the Scotia Sea (South Atlantic) are dominated in terms of numbers and biomass by penguins, seals and cetaceans (Laws 1977, Croxall et al. 1985). In the region of the island of South Georgia, Antarctic fur seals Arctocephalus gazella and macaroni penguins Eudyptes chrysolophus are the dominant species. Both prey primarily on macrozooplankton, especially Antarctic krill Euphausia superba (Croxall et al. 1988). Both also breed on land and raise offspring on food gathered during foraging trips to sea. This limits their foraging range (Boyd 1998) which means there is greatest potential for local inter- and intra-specific competition during summer when offspring are reared. Their absence from the island of South Georgia in winter may indicate that they migrate to forage in other regions thus avoiding 
local competition for resources at a time of year when zooplankton growth and reproduction are low (Raymont 1983). Summer krill abundance in the region around South Georgia also varies between years (Brierley et al. 1999). This leads to a non-linear response on the part of the penguins and fur seals (Boyd \& Murray 2001) which suggests that food is a limiting resource for these species.

An essential step in the assessment of the mechanisms underlying predator responses to changes in prey abundance is to understand where food is obtained. In the present study, we examined the spatial distribution of foraging by Antarctic fur seals at the island of South Georgia (South Atlantic). We concentrated upon the distribution of adult females because of their importance in determining the dynamics of the population. We cannot yet measure prey and predator dispersion simultaneously although this could be approached by using correlation analysis within the context of a geographical information system (GIS) (Guinet et al. 2001, Bjørge et al. 2002). There are indications that the scales of foraging in the Antarctic fur seal are similar to the spatial scales of krill swarm distributions (Boyd 1996), but the high spatial and temporal autocorrelation within animal tracking data of the type used in the present study make standard GIS approaches invalid. Nevertheless, physical features such as the bathymetry of the continental shelf around South Georgia, tend to be good proxys for plankton distributions (Priddle et al. 1988, Murphy 1995, Atkinson et al. 1990). Knowledge about the spatial distribution of foraging in relation to physical features and their constancy through time, provides a basis for predicting how environmental changes influence predator populations.

Our main objective was to examine the inter-annual and inter-seasonal changes in the foraging distribution of Antarctic fur seals and to relate this to features of the bathymetry of the region and to the presence of sea ice. To achieve this, we examined differences in foraging behaviour in both space and time. In addition, we used the empirical distribution of foraging around South Georgia during summer to interpolate a foraging distribution for the whole population of breeding females and thus estimate the local impact of fur seals on marine resources.

\section{MATERIALS AND METHODS}

A series of 3 experiments was carried out from 1995 to 1999 mainly at Bird Island, South Georgia $\left(54^{\circ} \mathrm{S}\right.$, $38^{\circ} \mathrm{W}$ ). Throughout the study, foraging was defined by the presence of diving in female fur seals. This is based upon the observation that there is a close link between the amount of diving by an individual and energy gain when averaged over whole foraging trips (Arnould et al. 1996) and also by recent observations of krill encountered during dives (Hooker et al. 2002). Therefore, we assumed that fur seals tended only to dive (depth $>2 \mathrm{~m}$ ) while they were foraging.

Spatial pattern of foraging. This was investigated using satellite tracking methods (Boyd et al. 1998). Expt 1 tested the hypothesis that there were significant changes in the foraging distribution between years for a population of female fur seals foraging from the same location in each year. Expt 2 tested the hypothesis that there were differences in the foraging location of lactating females when foraging from different locations at South Georgia. Expt 3 tested the hypothesis that female fur seal foraging distributions differed between summer and winter.

Expt 1: Interannual variation in foraging locations. Platform transmitter terminals (PTTs) (1995 \& 1996: Wildlife Computers, $1 \mathrm{~W}, 250$ to $500 \mathrm{~g}$, up to $15 \times 9 \times$ 3 cm; 1997 \& 1998: Telonics ST-10, 0.5 W, 200 g, $10 \times$ $4 \times 2.5 \mathrm{~cm}$ ) were deployed on lactating female Antarctic fur seals at Bird Island (South Georgia, $54^{\circ} \mathrm{S}, 38^{\circ} \mathrm{W}$ ). PTTs were attached with epoxy glue to the hair along the dorsal midline between the scapulae. Boyd et al. (1997) showed that the largest versions of these PTTs (used during 1995 and 1996) significantly reduced swimming speed and increased foraging trip duration but there is no evidence that this changed the foraging location. PTT signals were received by the Argos Satellite System. The PTTs had a minimum transmission interval of $45 \mathrm{~s}$, and they only operated when the saltwater switch, located close to the base of the antenna, showed that the antenna was out of the water. There was no duty cycling of the PTTs, but they were programmed to switch off after the animals had spent $1 \mathrm{~h}$ out of the water. Only Argos location classes 0 to 3 were used to determine the location. The precision was $0.001^{\circ}$ of latitude and longitude $(\sim 111 \mathrm{~m})$ and the mean accuracy was $8.6 \mathrm{~km}$ (Boyd et al. 1998). A filter was applied to the satellite-recorded locations to exclude outliers, defined as locations that required the animal to swim at $>2.5 \mathrm{~m} \mathrm{~s}^{-1}$ to reach the location from the previous plausible track or to return to the subsequent plausible track. This speed is slightly greater than the maximum sustained swimming speed (Boyd et al. 1995, Boyd et al. 1997). During 1995 and 1996, PTTs were deployed on individuals for 2 foraging trips, but for the purpose of statistical analyses, these were considered as a single trip. In the other years the deployments lasted for 1 foraging trip per individual. Details of the deployments during each year are given in Table 1.

Information about diving was obtained from each individual that carried a PTT. Time-depth recorders 
Table 1. Arctocephalus gazella. Deployments of satellite platform transmitter terminals (PTTs) and time-depth recorders (TDRs). Only those seals with $>5$ locations during a deployment were included in the analysis. Year: given as year in which austral summer ended

\begin{tabular}{|lcccccc|}
\hline Location & Year & Expt & $\begin{array}{c}\text { Date } \\
\text { range }\end{array}$ & Seal mass (kg) & $\begin{array}{c}\text { Deployments } \\
\text { Duration (d) } \\
\text { Median }\end{array}$ & $\begin{array}{c}\text { No. of locations } \\
\text { Mean } \pm \text { SD }\end{array}$ \\
\hline Bird Island & 1995 & 1 & 4 Dec-14 Feb & $36.5 \pm 5.0$ & 6.4 & $17.8 \pm 8.7$ \\
Bird Island & 1996 & 1 & 8 Dec-21 Mar & $41.0 \pm 3.7$ & 14.0 & $31.7 \pm 29.2$ \\
Bird Island & 1997 & 1 & 4 Dec-14 Mar & $39.6 \pm 4.2$ & 8.3 & $36.2 \pm 14.7$ \\
Stromness Bay & 1998 & 2 & 18 Jan-26 Feb & $32.3 \pm 5.7$ & 5.1 & $28.2 \pm 11.2$ \\
Bird Island & 1998 & 1 \& 2 & 14 Jan-11 Mar & $38.4 \pm 4.7$ & 6.1 & $37.7 \pm 21.7$ \\
Bird Island & 1999 & $3^{\mathrm{a}}$ & 5 Apr-15 Aug & $45.3 \pm 6.8$ & 88.4 & $994.7 \pm 538.3$ \\
a Without TDR & & & & & & \\
\end{tabular}

(TDR, Wildlife Computers, MK V and MK VII; resolution $1 \mathrm{~m})$ were programmed to measure depth at 10 (1995 and 1996) and $5 \mathrm{~s}$ (1997 and 1998) intervals for whole foraging trips. These records were retrieved from the memory of the TDR when seals returned ashore to feed their pups. Purpose-built software was used to analyse these records for individual dives (defined as excursions to depths $>2 \mathrm{~m}$ ).

We assumed that diving was indicative of foraging in fur seals, so we used diving location as a surrogate for foraging location. The location of each dive was estimated by interpolating along a direct line between successive locations provided by the satellite. This assumed that the fur seal moved at approximately constant speed between successive location fixes. Therefore, the position of each dive was estimated from the time of the dive relative to those of the location fixes before and after the dive. The position determined in this way was rounded to the nearest $0.1^{\circ}$ of latitude and longitude which approximates to $10.8 \mathrm{~km}$ and $6.6 \mathrm{~km}$ respectively at South Georgia.

Expt 2: Variation in foraging location between lactation sites. Although it seemed probable that female Antarctic fur seal foraging locations were determined to some extent by the location at which the pup was being fed, there was uncertainty to what extent animals traveling from locations in the same potential foraging range (up to 250 to $300 \mathrm{~km}$; Boyd 1999) would differ in their foraging locations. Using the same method as described for Expt 1, we examined the foraging distribution of lactating fur seals that were traveling from 2 sites separated by $90 \mathrm{~km}$, which was approximately one-third of the maximum foraging range in summer (Boyd 1999). Fur seals from each of the sites would, therefore have been capable of foraging close to either site. The experiment took place in January and February 1998 with concurrent deployments of satellite tags and TDRs on lactating female fur seals at Bird Island (as for Expt 1) and at Stromness Bay $\left(54.2^{\circ} \mathrm{S}, 36.6^{\circ} \mathrm{W}\right)$ (Table 1$)$. Since the reproductive cycle of Antarctic fur seals at South Georgia is highly synchronised across the island, females at both sites were at a similar stage of lactation.

Expt 3: Variation in foraging locations between winter and summer. In March and April 1999, we deployed PTTs on 10 adult female fur seals using the same methods as described in Expt 1 (Table 1). All females had reared a pup at Bird Island during the previous $4 \mathrm{mo}$ and had, therefore, been foraging in the vicinity of Bird Island in accordance with the patterns observed from Expt 1. The timing of the deployments coincided with pup weaning. However, in these cases, no TDR was deployed, because we had a low expectation of recovering the TDR to obtain diving data.

Statistical analysis. Differences in the foraging distribution between years were examined using a modified Kruskal-Wallis 1-way ANOVA by ranks. The extent of the geographical range across all years was defined by the maximum and minimum latitudes and longitudes within the data. These maxima and minima were used to define a grid placed over the range of the animals. The resolution of the grid varied from 0.1 to $1.0^{\circ}$ latitude and longitude. The number of dives made by each individual was summed for each grid square. Since we wished to compare between the spatial distributions of dives from each year of the study, the total number of dives obtained among years was obtained by summing all of the dives made by individuals among years after normalising for differences in the total number of dives made by individuals.

Differences in the distributions at spatial scales from to 0.1 to $0.5^{\circ}$ latitude and longitude were assessed by ranking the individual grid squares among all years and calculating the Kruskal-Wallis statistic with correction for tied observations (Eq. 8.5 in Siegel \& Castellan 1988). The analysis was restricted only to those grid squares in which animals were observed to have dived in at least one of the years. Although the results of this calculation for the sample sizes encountered in the present study would usually follow a $\chi^{2}$ distribution, 
we carried out Monte Carlo simulation to help provide a more robust estimate of the critical value that indicated the level of difference in the distribution among years. This was because the grid squares used by an individual animal could not be considered to be independent. Thus, reallocating the diving distributions of individual seals to different years at random allowed us to test the hypothesis that there was no difference in the distribution among years. If there was no significant difference, the Kruskal-Wallis statistic for the observed pattern would lie within the distribution of the statistic based on 10000 bootstrapped samples from the pooled empirical distribution of foraging ranges from all years.

The Kruskal-Wallis statistic used in this context may also be viewed as an index of overlap with 0 indicating complete overlap and $\infty$ indicating no overlap.

Estimation of spatial distribution of foraging by the population. In order to interpolate from our empirical distribution of the foraging range of our sample from the population, we developed an empirically-based function that could be applied to parts of the population in unsampled geographical regions. We tested the degree to which this function provided an accurate view of the foraging distribution by applying the function derived from seals at Bird Island to those at Stromness and vice versa.

If a female Antarctic fur seal forages in support of its own maintenance and that of its offspring, it is restricted in the range of travel by the necessity to return to the pup before the pup starves (Boyd 1999). Thus these individuals forage from a central point defined by the offspring but, since offspring move over limited distances $(<1$ to $2 \mathrm{~km})$, this can be more conveniently defined by a geographical location. Let $M$ be the random variable describing the location of a foraging event, which in this study is described by the presence of a dive, at any time during its foraging trip. This will lead to a probability density function (PDF) $f_{M}(m \mid i)$ for the location of a foraging event during a foraging trip where $M=m$ for any realization. If there are $N$ individuals in the population occupying site $i$ then the absolute density of foraging events will be $N_{i}$ $\left[f_{M}(m \mid i)\right] p_{\mathrm{s}}$, where $p_{\mathrm{s}}$ is the probability that an individual is at sea as opposed to being ashore feeding its pup.

However, the distribution of $M$ can most conveniently be described by 2 other random variables: $L$, the distance of $M$ from $i$, and $\theta$, the bearing from $i$ relative to an imaginary line running parallel to the coastline. These in turn will have PDFs described as $f_{L}(l \mid i)$ and $f_{\theta}\left(\theta^{*} \mid i\right)$. Thus, the position coordinates $\left(x_{i}, y_{i}\right)$ of $M$ were defined by the functions $g_{i}(x, y \mid l)$ and $g_{i}\left(x, y \mid \theta^{*}\right)$, assuming that 1 and $\theta^{*}$ vary independently. The generalized probability density function for an animal being at $(x, y)$ can be defined as follows:

$$
f_{i}(x, y \mid i)=\left\{\begin{array}{l}
\int_{0}^{\infty} g_{i}(x, y \mid l) f_{L}(l \mid i) \mathrm{d} l \\
0 \\
\int_{0}^{180} g_{i}\left(x, y \mid \theta^{*}\right) f_{\theta}\left(\theta^{*} \mid i\right) \mathrm{d} \theta
\end{array}\right.
$$

There are no a priori decision criteria for defining either $f_{L}(1 \mid i)$ or $f_{\theta}\left(\theta^{*} \mid i\right)$. Therefore, the empirical estimates of $f_{i}(x, y \mid i)$ from Expt 2 were used to develop empirical distributions of $f_{L}(1 \mid i)$ and $f_{\theta}\left(\theta^{*} \mid i\right)$. These were generalized by fitting a gamma function to each distribution by least squares. The parameters $c$ and $b$ defined the shape and scaling respectively of the gamma functions (Evans et al. 1993). Since Expt 2 involved examining animals foraging from 2 locations, the distributions from each location were used to test the efficacy of providing an estimate of the foraging
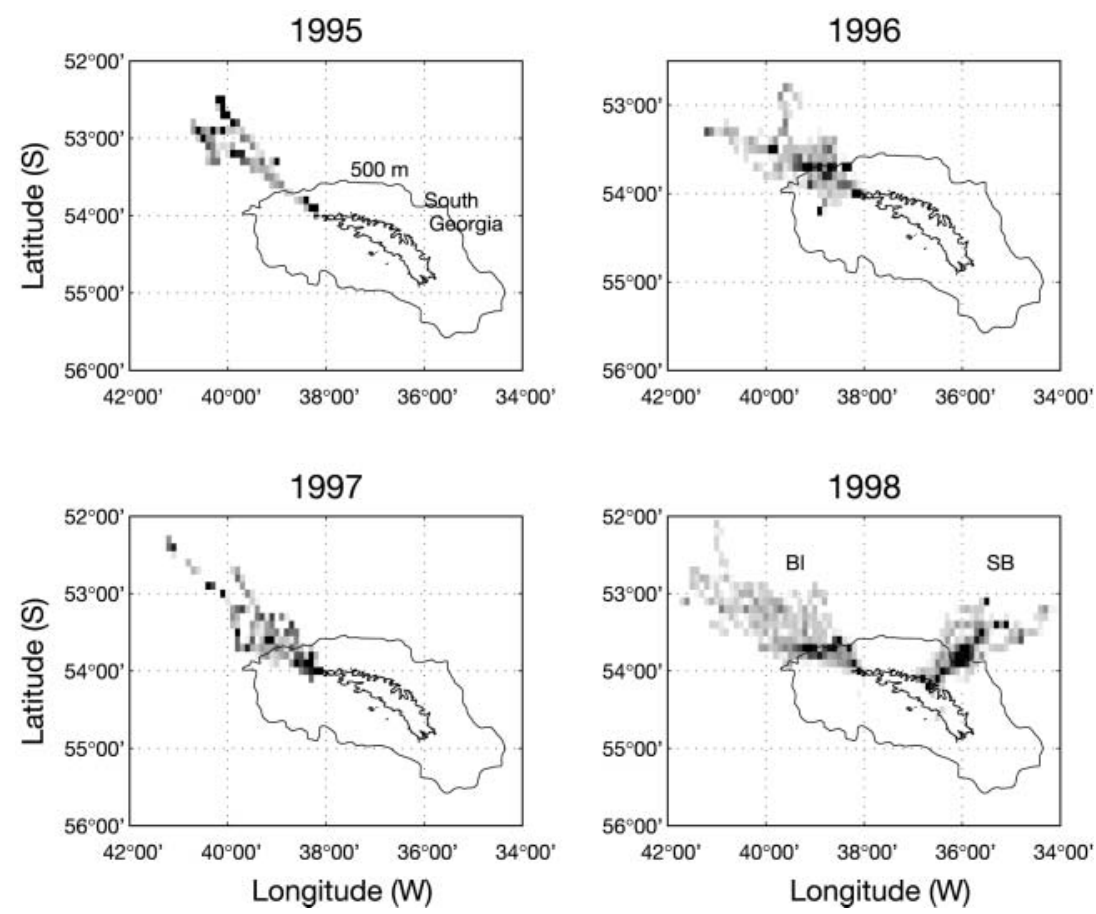

Fig. 1. Arctocephalus gazella. Distribution of foraging by females supporting pups at Bird Island during 1995 to 1998 , by a $0.1^{\circ} \times 0.1^{\circ}$ grid. Percentage frequency from 0 to $>2 \%$ (white: low value; black: high value). The $500 \mathrm{~m}$ isobath around South Georgia is shown to illustrate the extent of the continental shelf. The 1998 panel shows densities of fur seals foraging from Bird Island (BI) and Stromness Bay (SB) 
distribution from the ith colony. Thus the population distribution is given by:

$$
f(x, y)=\sum_{i=1}^{n} f_{i}(x, y \mid i) N_{i}
$$

where there are $n$ colonies or locations from which these fur seals forage.

\section{RESULTS}

\section{Expt 1: Interannual variation in foraging locations}

Examination of the tracks and diving locations of female fur seals which were rearing pups at Bird Island showed that they always moved north-west from Bird Island (Fig. 1). In 1996 and 1998 the principal foraging areas were at the continental shelf margin. There was no strongly significant difference in the foraging distribution between years, and differences only existed at a relatively fine scale of spatial resolution (Table 2). This result was based upon a 1-way ANOVA by ranks used to test for differences among years after accounting for

Table 2. Arctocephalus gazella. Foraging range overlap amongst years for lactating seals from Bird Island during $1994 / 95$ to $1998 / 99$. Results of 1 -way ANOVA by ranks. The $K W$ statistic is an index of overlap, with higher value indicating lower overlap. The probability level was set by resampling individual fur seals at random and re-allocating them to years at random

\begin{tabular}{|crc|}
\hline Spatial scale $\left({ }^{\circ}\right.$ lat./long. $)$ & $K W$ & $\mathrm{p}$ \\
\hline $0.1 \times 0.1$ & 1062 & 0.01 \\
$0.2 \times 0.2$ & 257 & 0.02 \\
$0.5 \times 0.5$ & 22 & 0.10 \\
\hline
\end{tabular}

Table 3. Arctocephalus gazella. Bivariate Spearman rank correlations between the percentage frequency of seal foraging taking place in each $0.1^{\circ} \times 0.1^{\circ}$ grid square. Only grid squares in which a fur seal had been recorded during 1 of the 2 years in each comparison were used in the analysis

\begin{tabular}{|cccrr|}
\hline Year & Spatial scale ( ${ }^{\circ}$ lat./long.) & 1996 & 1997 & 1998 \\
\hline \multirow{4}{*}{1995} & $0.1 \times 0.1$ & -0.41 & -0.25 & -0.04 \\
& $0.2 \times 0.2$ & -0.36 & -0.10 & 0.15 \\
& $0.5 \times 0.5$ & -0.22 & 0.38 & 0.45 \\
1996 & $0.1 \times 0.1$ & & & \\
& $0.2 \times 0.2$ & & 0.09 & 0.16 \\
& $0.5 \times 0.5$ & & 0.20 & 0.32 \\
1997 & $0.1 \times 0.1$ & & & 0.73 \\
& $0.2 \times 0.2$ & & & 0.21 \\
& $0.5 \times 0.5$ & & & 0.42 \\
& & & & \\
\hline
\end{tabular}

both the difference in sample sizes between years and serial correlation in the data from each individual seal. A similar analysis involving bivariate comparisons between years showed that the degree of correlation between the distributions estimated in each year increased with increasing spatial scale (Table 3). Due to differences in sample size in each year, and because of the serial correlation of foraging location within the foraging of individuals, it is difficult to estimate the statistical significance of these correlations. However, they tend to show that the dispersion of foraging in 1995 differed most from the other years.

\section{Expt 2: Variation in foraging location between lactation sites}

During 1998, the foraging distribution of lactating fur seals was examined at 2 locations within the breeding range of the species at South Georgia. In contrast to the fur seals from Bird Island, fur seals from Stromness Bay moved northeast and the regions of maximum foraging density were located close to the margin of the continental shelf (Fig. 1, 1998). This showed clearly that fur seals tended to forage along a bearing that was approximately perpendicular to the coastline and to the margin of the continental shelf. There was no overlap in the foraging ranges of fur seals from the 2 sites and the distance travelled, which represented movement to the continental shelf edge, was similar at both sites.

\section{Expt 3: Variation in foraging locations between winter and summer}

The overall dispersion of fur seals during winter showed that there were particular foci of abundance (Fig. 2). This assumes that the number of determinations of position was proportional to the time spent in an area by the fur seals. There was a particular focus to the northwest of South Georgia in the region used by these individuals during the summer (Fig. 1). This occupied the region between South Georgia and the approximate location of the Antarctic Polar Frontal Zone (Fig. 2). There was a second focus to the south of South Georgia which corresponds to the approximate position of the edge of the Antarctic sea ice. There were additional foci associated with the continental shelf of South America along the coast of Patagonia and to the north of the Falkland Islands. These were mainly caused by individual animals concentrating their activities in these regions for extended periods. Each individual responsible for the foci over the Patagonian Shelf is designated as A to D in Fig. 2. Three 


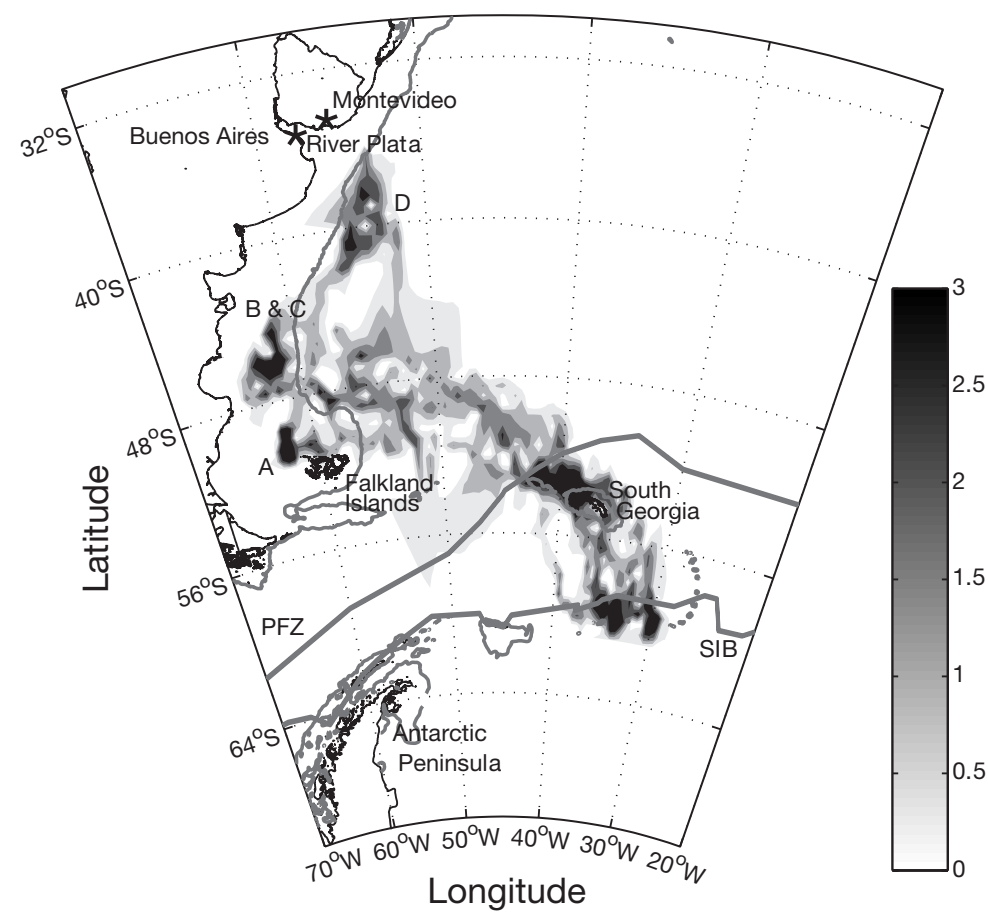

Fig. 2. Arctocephalus gazella. Mean dispersion of 10 adult females during the 4 months after the end of lactation (April-August) as a percentage of the total number of locations on a scale of 0 to $3 \%$ within $0.5^{\circ} \times 0.5^{\circ}$ grid squares. Contouring derived from a cubic spline fit to the data. PFZ: Polar Frontal Zone; SIB: maximum northern extent of the Antarctic sea ice; $500 \mathrm{~m}$ isobath shown to illustrate continental shelf margins. A-D: foci of activity of 4 individuals on the continental shelf of South America

of these individuals foraged over the continental shelf (A to C) whereas the other (D) concentrated its foraging close to the outer edge of the continental shelf.

The movement of seals away from South Georgia after the end of the breeding season in April is illustrated in Fig. 3. In most cases, this showed clear peaks in the rate of travel. Some individuals (e.g. w5803 and w5581) did not remain within their summer foraging range in the South Georgia region beyond the end of April. Others (e.g. w5797 and w5757) delayed their departure from the region until mid-June. The general direction of movement for each individual is designated by ' $\mathrm{N}$ ' for northwest or ' $\mathrm{S}$ ' for southeast in parentheses in Fig. 3. None of the individuals remained within the summer foraging range during the experiment. Even w5767, whose transmitter failed after only $10 \mathrm{wk}$ and whose rate of movement was relatively slow, had moved south outside the normal summer foraging range. The most rapid rate of movement was recorded by w5801 (Fig. 3) at almost $971 \mathrm{~km} \mathrm{wk}^{-1}$. This represents a mean straight-line swimming speed of $1.6 \mathrm{~m} \mathrm{~s}^{-1}$. A total of 7 individuals moved away from South Georgia to the northwest and 3 individuals went to the region of the ice edge about $500 \mathrm{~km}$ from South
Georgia. The transmitters on 3 of those that went northwest (w5803, w5797, w5757) stopped working at around the time they reached the edge of the Patagonian Shelf. During July and August, individuals remained in the regions they had traveled to, apart from 2 of those (w5793, w5727) that had gone southeast to the region of the ice edge. As indicated by the multimodal distributions of the rate of movement (Fig. 3), these individuals had 2 and 1 cycle respectively of migration during the measurement period. In each case, they moved to the region of the ice edge and then returned to the South Georgia region. In one case (w5793) the recording time was sufficiently long to show this individual moving back to the ice edge. Each of these migratory cycles appeared to last about 2 mo. No fur seal went to both the Patagonian Shelf and the ice edge.

\section{Estimation of summer foraging density at South Georgia}

We considered the spatial distribution of foraging by lactating fur seals combined across all 4 years of data obtained during pup rearing. This was compiled by combining the data among years for fur seals from Bird Island (Fig. 1), and the result is shown in Fig. 4b. Similarly the observed spatial distribution of foraging for the fur seals from Stromness Bay is illustrated in Fig. 4d. The estimated spatial distributions for fur seals from the 2 source areas (Fig. 4a,c respectively) explained 42 and $53 \%$ of the variance, respectively, in the observed spatial distributions (Spearman rank correlation of presence in $0.1 \times 0.1$ grid squares). A visual assessment also suggests that the interpolation provided a reasonable representation of the spatial distribution of foraging from the 2 land sites. The best-fit values of the shape parameter $(C)$ of the gamma functions describing the distance traveled on a foraging trip and the angle of travel away from the colony were 5 and 1.5, respectively. Similarly, the best-fit values of the scaling parameter $(b)$ of the same gamma functions were 20 and 7 , respectively.

We then applied the same function to all the other sites at South Georgia as defined by Boyd (1993). Weighting the simulation by the number of fur seals at each site in 1991 and using 20000 determinations, we estimated the spatial distribution of foraging for lactating female fur seals at South Georgia in 1991 (Fig. 5). The spatial distribution showed 3 main concentrations to the north, west and south of South Georgia with the 
largest being mainly to the south. Very few females foraged in the region used by fur seals from Stromness Bay. This arose partly because the population data used in Fig. 5 were for 1991, when few fur seals were breeding there, and partly because the numbers at Stromness Bay are extremely small, relative to the total fur seal population at South Georgia.

\section{DISCUSSION}

This study demonstrates the following aspects in lactating Antarctic fur seal behaviour: (1) consistency (at the spatial scales measurable) in the spatial distributions of foraging areas among years; (2) location of foraging areas at the continental shelf edge; (3) migration to other foraging grounds in the winter (non-breeding) season; and (4) concentration of the spatial impact in summer on specific regions around the island of South Georgia.

\section{Distribution during the breeding season}

Fur seals swam similar distances offshore from both sites at South Georgia. Although there appeared to be a relationship between fur seal foraging patterns and bathymetry, we suggest that, while bathymetry may be the proximate cause of the observed foraging patterns, the ultimate cause will be the distribution of food (Guinet et al. 2001). The shelf edge at South Georgia has a major influence on water mass distribution (Brandon et al. 1999), with fresher, warmer and less stratified water over the shelf, and colder, more saline and more stratified water in the deep ocean. The junction of these occurs at a frontal zone near the $500 \mathrm{~m}$ isobath. Using data sets from 1998 also used in the present study, Boyd et al. (2001) related the diving behavior of female fur seals to the ocean temperature and found that foraging concentrated on areas with deep, oceanic water, including upwelling sectors over the shelf. Consequently, the foraging patterns reflect the distributions of water masses which influence the distribution of the krill on which fur seals feed (Murphy et al. 1998).

Therefore the distributions of fur seal foraging among years probably reflects interannual variation in the characteristics and distribution of the water masses
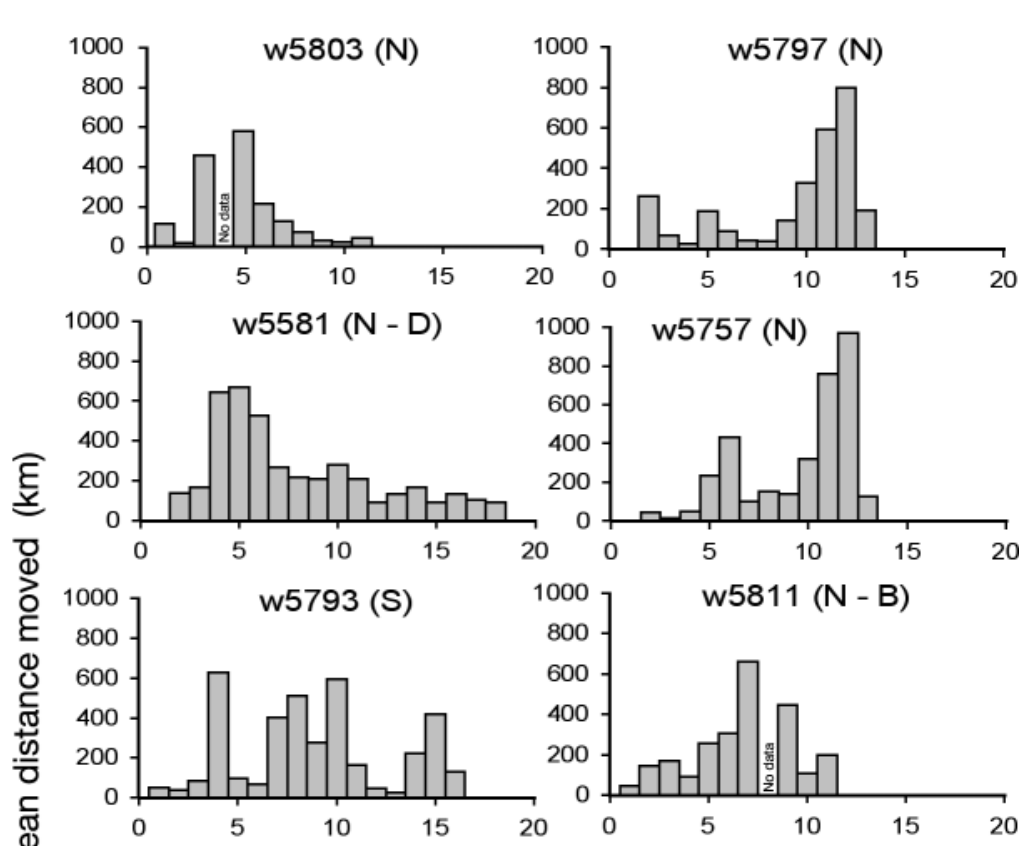

$1000] \quad\left[\begin{array}{l}w 5801(N-C)^{1000} \\ 7\end{array} \quad\right.$ w5773 (N - A)
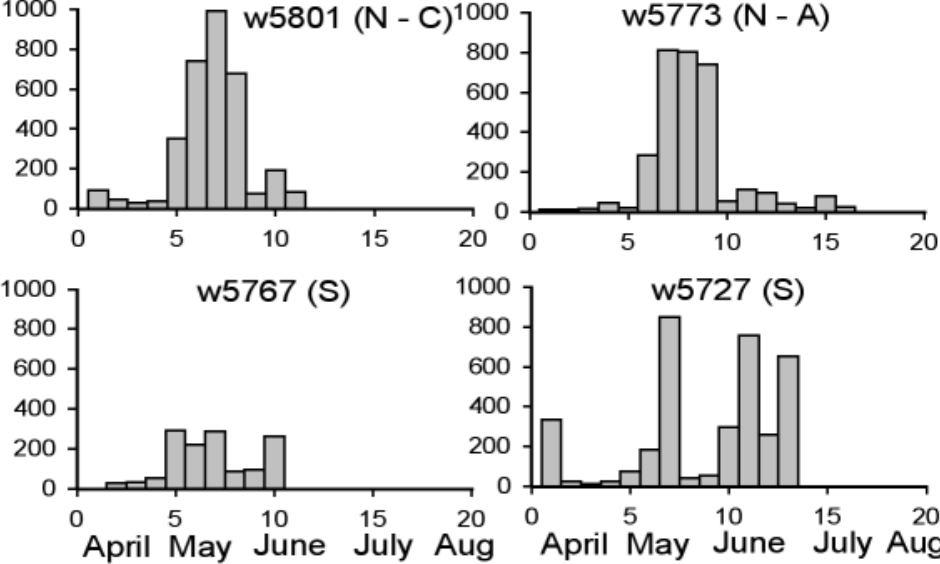

Time (weeks)

Fig. 3. Arctocephalus gazella. Mean distance moved per week by 10 adult females after the end of lactation. The first letter in parentheses after the number of the animal denotes whether the animals moved northwest $(\mathrm{N})$ or southeast (S) from South Georgia; the second letter denotes individuals referred to in Fig. 2

in the region. We found very little variability in the foraging distributions among years, but the small differences observed around the shelf break could have been driven by changes in the distribution of water masses and the location or strength of oceanographic fronts (Brandon et al. 1999).

During breeding, Antarctic fur seals at the island of South Georgia appeared to forage as close as possible to the location of the pup and colony-specific movement patterns were related to the bathymetric gradient (Bonadonna et al. 2001). Prior to 1998, there was no information about the foraging distribution of fur seals 

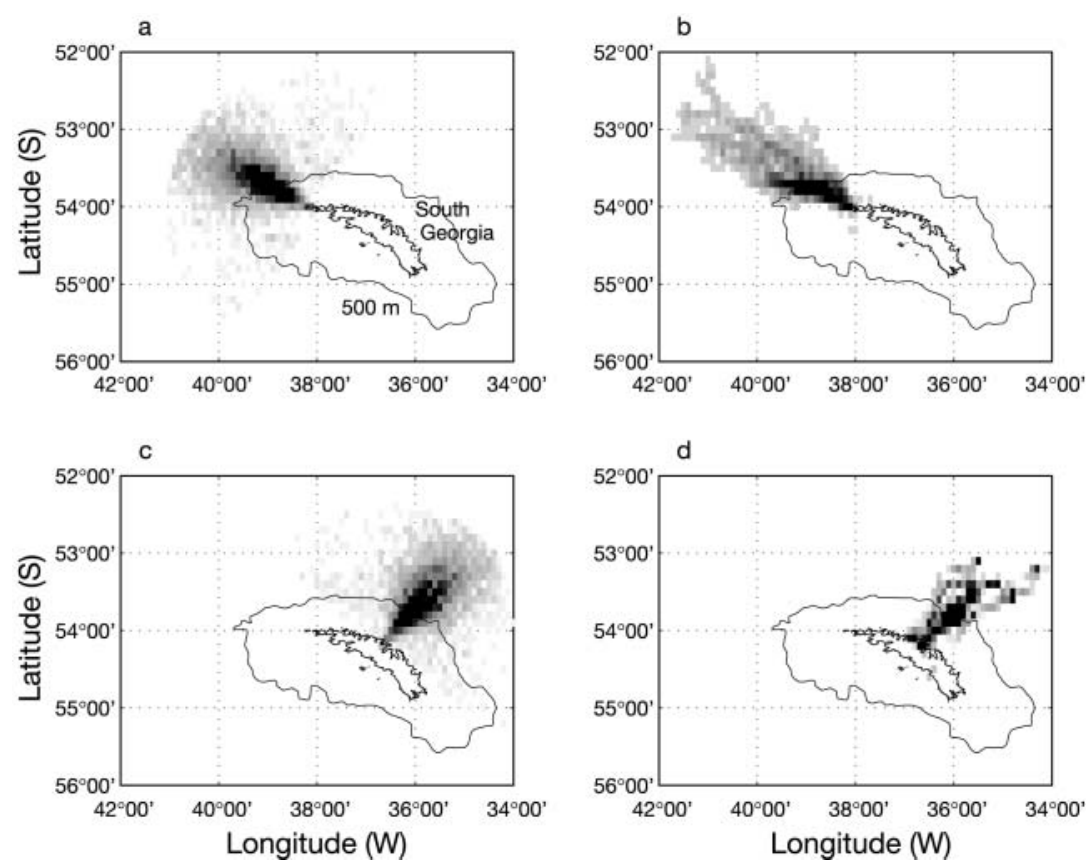

Fig. 4. Arctocephalus gazella. Comparison between the best-fit representation of the foraging distribution $(\mathrm{a}, \mathrm{c})$ and the observed foraging distribution $(\mathrm{b}, \mathrm{d})$ of lactating seals with offspring at Bird Island $(a, b)$ and Stromness Bay $(c, d)$. Spatial distribution represented by the shading of $0.1^{\circ} \times 0.1^{\circ}$ grid squares (dark: high density; light: low density)

except from studies conducted at Bird Island. Since Bird Island is at the centre of the breeding range and was one of the first sites to be colonised at South Georgia, it could have been possible that all animals from South Georgia relied on feeding in the same location as those from Bird Island. This is clearly not the case as demonstrated by the difference in the spatial distribution of foraging fur seals at the 2 sites used in Expt 2. These sites were separated sufficiently to resolve differences, but not so far as to make it impossible for fur seals from either site to forage in the same locations. We observed no overlap of foraging regions from the 2 sites, which confirms that fur seals at South Georgia can find sufficient food by swimming down the bathymetric gradient towards the continental shelf edge.

\section{Spatial distribution of foraging for the whole population}

We used the apparent consistency of fur seal foraging from the coast to the continental shelf edge to develop a simple system for interpolation of the spatial distribution of foraging for the whole population. The predicted distribution needs to be tested formally, possibly by using counts from survey vessels in the region. However, a ship survey of seals and seabirds carried out in summer 1986 along radial transects centered on the western tip of South Georgia showed concentrations of fur seals which are consistent with the distribution predicted in this study (Hunt et al. 1992). In particular, the greatest densities were observed over the continental shelf to the southwest of South Georgia in the same region as suggested by our interpolation.

According to the algorithm defined by Boyd (2002), the total food requirement of female Antarctic fur seals at the island of South Georgia in the summer of 1991 was $3.25 \times 10^{5} \mathrm{t}(\mathrm{SE}=$ $5862 \mathrm{t}$ ). Therefore, on the scale shown in Fig. 5, this represents a range of food consumption per $0.1^{\circ} \times 0.1^{\circ}$ grid square of up to $1.6 \times 10^{3} \mathrm{t}\left(\right.$ mean $\left.=0.2 \times 10^{3} \mathrm{t}\right)$, but the distribution of food consumption is highly skewed (Fig. 6) reflecting the extremely patchy nature of the foraging distribution.

The fine-scale distribution of food consumption observed in the present study has some similarities to the distribution of fishing for krill around South Georgia (Trathan et al. 1998). Although the krill fishery mainly occurs in the winter, it is also concentrated at the margins of the continental shelf. However, the spatial distribution of foraging probably has greatest relevance to understanding the dynamics of krill populations in the region (Murphy 1995) and, in particular, the degree to which predators like Antarctic fur seals can deplete krill populations in specific locations. Estimates of krill abundance at South Georgia

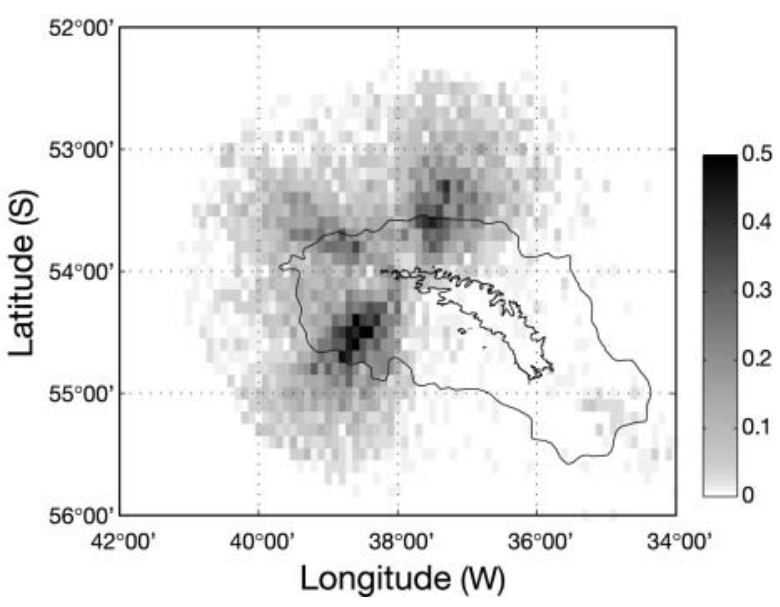

Fig. 5. Arctocephalus gazella. Predicted spatial distribution of foraging by lactating seals at South Georgia. Data to the last survey in 1991 


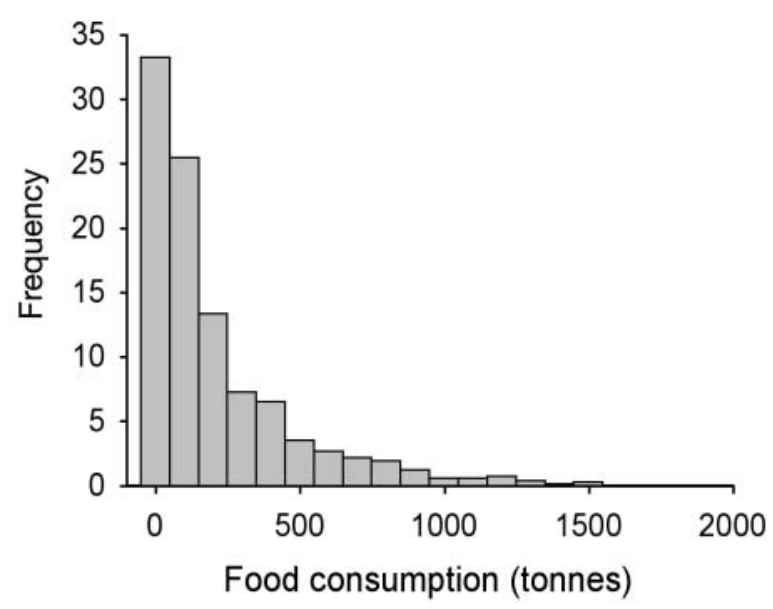

Fig. 6. Arctocephalus gazella. Frequency distribution of predicted mass of food consumption by lactating seals for each $0.1^{\circ} \times 0.1^{\circ}$ grid square in which they were likely to feed, based on the results illustrated in Fig. 5

(Brierley et al. 1999) showed a mean density among years of $35 \mathrm{~g} \mathrm{~m}^{-2}$ (range 6.4 to $65.8 \mathrm{~g} \mathrm{~m}^{-2}$ ) in the region. Scaled up to a $0.1^{\circ} \times 0.1^{\circ}$ grid (approximately $70 \mathrm{~km}^{2}$ ), and assuming that the estimates produced by Brierley et al (1999) apply to the whole of the fur seal foraging range, this is a mean krill biomass of $2.5 \times 10^{3} \mathrm{t}$ (range 0.4 to $4.6 \times 10^{3} \mathrm{t}$ ) per grid square. Not all of this krill will be available to fur seals, because it may be at too great a depth, and the krill is also exploited by other predators such as cetaceans, penguins and other seabirds, fish, squid, and fur seals other than just adult females. The mean food consumption by female fur seals per $0.1^{\circ} \times 0.1^{\circ}$ grid square of $0.2 \times 10^{3} \mathrm{t}$ suggests that female fur seals have a potentially dominant role amongst the top predators of krill, and that they are potentially susceptible to changes and variation in krill availability, particularly in years of low krill abundance. Nevertheless, averaged over the whole foraging range during the breeding season (December to March), adult female fur seals take less that one-tenth of the krill biomass in an average year, even without accounting for the possible effects of the movement of krill driven by oceanographic flux through the region of South Georgia (Murphy 1995).

\section{Critical habitats for fur seals}

This study suggests that Antarctic fur seals have few options about where to feed during lactation. Krill acoustic biomass at South Georgia was similar in each of the years examined in this study (Brierley et al. 1999), so it is still unclear what effects food shortage might have upon the foraging distribution. Nevertheless, fur seal lactation success could be influenced by local (10s to $100 \mathrm{~s} \mathrm{~km}$ ) changes in the distribution of food brought about by variations in local oceanographic conditions, as much as it can be by regional changes in food production. It is also probable that intensive fishing activity for krill in the regions of highest fur seal concentration would further limit the food available for fur seals during lactation.

In contrast, during the winter season adult female fur seals disperse over a wide area and possibly exploit widely varying food sources. They appear to localise their foraging activities in areas of known high productivity in association with the continental shelf of South America (Glorioso \& Flather 1995) and the edge of the Antarctic pack ice (Ainley et al. 1986, Sullivan et al. 1988). The contrasting directions of movement and different foci of foraging activity of fur seals, either to the north or to the south, could be characteristic of the individuals. The tracking of individuals during successive years would be required in order to test this. The observation of the single individual that returned to forage in the same region at the ice edge after making a return trip to South Georgia suggests that individuals may show consistency in their foraging locations even when they are not constrained to foraging within certain areas by having a pup.

Similar trans-oceanic migrations to localised foraging grounds have been observed in elephant seals (McConnell \& Fedak 1996, Le Boeuf et al. 2000) and grey seals (McConnell et al. 1999). The studies of grey seals in particular have suggested that these animals return repeatedly to regions of high productivity. The degree to which individuals rely for their survival and reproductive success upon the predictability of finding food in these locations could determine population trajectories.

Acknowledgements. We are grateful to field and scientific staff at the British Antarctic Survey's Bird Island Station for assistance. In particular, R. Taylor and A. Morton provided invaluable assistance in the field. We are also grateful to Dr. S. K. Hooker and Prof. J. P. Croxall for providing criticism of an early version of this manuscript.

\section{LITERATURE CITED}

Agnew DJ (1997). The CCAMLR ecosystem monitoring programme. Antarct Sci 9:235-242

Ainley DG, Fraser WR, Sullivan CW, Torres JJ, Hopkins TL, Smith WO (1986) Antarctic mesopelagic micronektonevidence from seabirds that pack ice affects community structure. Science 232:847-849

Arnould JPY, Boyd IL, Speakman JR (1996) The relationship between foraging behaviour and energy expenditure in Antarctic fur seals. J Zool (Lond) 239:769-782

Atkinson A, Ward P, Peck JM, Murray AWA (1990) Mesoscale distribution of zooplankton around South Georgia. DeepSea Res 37:1213-1227 
Bjørge A, Bekkby T, Bakkestuen V, Framstad E (2002) Interactions between harbour seals, Phoca vitulina, and fisheries in complex coastal waters explored by combined Geographic Information System (GIS) and energetics modelling. ICES J Mar Sci 59:29-42

Bonadonna F, Lea MA, Dehorter O, Guinet C (2001) Foraging ground fidelity and route-choice tactics of a marine predator: the Antarctic fur seal Arctocephalus gazella. Mar Ecol Prog Ser 223:287-297

Boyd IL (1993) Pup production and distribution of breeding Antarctic fur seals (Arctocephalus gazella) at South Georgia. Antarct Sci 5:17-24

Boyd IL (1996) Temporal scales of foraging in a marine predator. Ecology 77:426-434

Boyd IL (1998) Time and energy constraints in pinniped lactation. Am Nat 152:717-728

Boyd IL (1999) Foraging and provisioning in Antarctic fur seals: interannual variability in time-energy budgets. Behav Ecol 10:198-208

Boyd IL (2002) Estimating food consumption of marine predators: Antarctic fur seals and macaroni penguins. J Appl Ecol 39:103-119

Boyd IL, Murray AWA (2001) Monitoring marine ecosystems using responses of upper trophic level predators. J Anim Ecol 70:747-760

Boyd IL, Bevan RM, Reid K (1995) Swimming speed and allocation of time during the dive cycle in Antarctic fur seals. Anim Behav 50:769-784

Boyd IL, McCafferty D, Walker TR (1997) Variation in foraging effort by lactating Antarctic fur seals: response to simulated increased foraging costs. Behav Ecol Sociobiol 40:135-144

Boyd IL, McCafferty DJ, Reid K,Taylor R, Walker TR (1998) Dispersal of male and female Antarctic fur seals (Arctocephalus gazella). Can J Fish Aquat Sci 55:845-852

Boyd IL, Hawker EJ, Brandon MA, Staniland IJ (2001) Measurement of ocean temperatures using instruments carried by Antarctic fur seals. J Mar Syst 27:277-288

Brandon MA, Murphy EJ, Whitehouse MJ, Trathan PN, Murray A, Bone DG, Priddle J (1999) The shelf break front to the east of the sub-Antarctic island of South Georgia. Cont Shelf Res 19:799-819

Brierley AS, Watkins JL, Goss C, Wilkinson MT, Everson I (1999) Acoustic estimates of krill density at South Georgia, 1981 to 1998 . CCAMLR Sci 6:47-57

Cairns DK (1987) Seabirds as indicators of marine food supplies. Biol Oceanogr 5:261-271

Croxall JP, Prince PA, Ricketts C (1985) Relationships between prey life-cycles and the extent, nature and timing of seal and seabird predation in the Scotia Sea. In: Siegfried WR, Condy PR, Laws RM (eds) Antarctic nutrient cycles and food webs. Springer, Berlin, p 516-533

Croxall JP, McCann TS, Prince PA, Rothery P (1988) Reproductive performance of seabirds and seals at South Georgia and Signy Island, South Orkney Islands 1976-1986: implications for Southern Ocean monitoring studies. In: Sahrhage D (ed) Antarctic ocean and resources variability. Springer, Berlin, p 261-285

Evans M, Hastings N, Peacock B (1993) Statistical distributions. Wiley, New York

Glorioso PD, Flarther RA (1995) A barotropic model of the currents off SE South America. J Geophys Res-Oceans 100:13427-13440
Guinet C, Dubroca L, Lea MA, Goldsworthy S, Cherel Y, Duhamel G, Bonadona F, Donnay JP (2001) Spatial distribution of foraging in female Antarctic fur seals Arctocephalus gazella in relation to oceanographic variables: a scale-dependent approach using geographic information systems. Mar Ecol Prog Ser 219:251-264

Hooker SK, Boyd IL, Jessop M, Cox O, Blackwell J, Boveng PL, Bengtson JL (2002) Monitoring the prey-field of marine predators: combining digital imaging with data logging tags. Mar Mamm Sci (in press)

Hunt GL Jr, Heinemann D, Everson I (1992) Distributions and predator-prey interactions of macaroni penguins, Antarctic fur seals, and Antarctic krill near Bird Island, South Georgia. Mar Ecol Prog Ser 86:15-30

Hyrenbach KD, Forney KA, Dayton PK (2000) Marine protected areas and ocean basin management. Aquat Conserv Freshw Ecosyst 10:437-458

Laws RM (1977) The significance of vertebrates in the Antarctic marine ecosystem. In: Llano GA (ed) Adaptations within Antarctic ecosystems. Proc 3rd SCAR Symp Antarctic biol. Smithsonian Institution, Washington, DC, p 411-438

Le Boeuf BJ, Crocker DE, Costa DP, Blackwell SB, Webb PM, Houser DS (2000) Foraging ecology of northern elephant seals. Ecol Monogr 70:353-382

McConnell BJ, Fedak MA (1996) Movements of southern elephant seals. Can J Zool 74:1485-1496

McConnell BJ, Fedak MA, Lovell P, Hammond PS (1999) Movements and foraging areas of grey seals in the North Sea. J Appl Ecol 36:573-590

Monaghan P (1996) Relevance of the behavior of seabirds to the conservation of marine environments. Oikos 77:227-237

Montevecchi WA (1993) Birds as indicators of change in marine prey stocks. In: Furness RW, Greenwood JJD (eds) Birds as monitors of environmental change. Chapman \& Hall, London, p 217-266

Murphy EJ (1995) Spatial structure of the Southern Ocean ecosystem: predator-prey linkages in Southern Ocean food webs. J Anim Ecol 64:333-348

Murphy EJ, Watkins JL, Reid K, Trathan PN and 6 others (1998) Interannual variability of the South Georgia marine ecosystem: biological and physical sources of variation in the abundance of krill. Fish Oceanogr 7:381-390

Priddle J, Croxall JP, Everson I, Heywood RB, Murphy EJ, Prince PA, Sear CB (1988) Large scale fluctuations in distribution and abundance of krill-a discussion of possible causes. In: Sahrhage D (ed) Antarctic ocean resources variability. Springer, Berlin, p 169-182

Raymont JEG (1983) Plankton and productivity in the oceans, Vol 2, Zooplankton. Pergamon Press, Oxford

Reid K, Croxall JP (2001) Environmental response of uppertrophic level predators reveals ecosystem change in an Antarctic marine ecosystem. Proc Roy Soc Lond B 268: $377-384$

Siegel S, Castellan, NJ (1988) Nonparametric statistics for the behavioral sciences. McGraw-Hill, New York

Sullivan CW, McClain CR, Comiso JC, Smith WO (1988) Phytoplankton standing crops within an Antarctic ice edge assessed by satellite remote-sensing. J Geophys Res Oceans 93:12487-12498

Trathan PN, Everson I, Murphy EJ, Parkes GB (1998) Analysis of haul data from the South Georgia krill fishery. CCAMLR Sci 5:9-30

Submitted: April 9, 2002; Accepted: July 16, 2002

Proofs received from author(s): September 9, 2002 